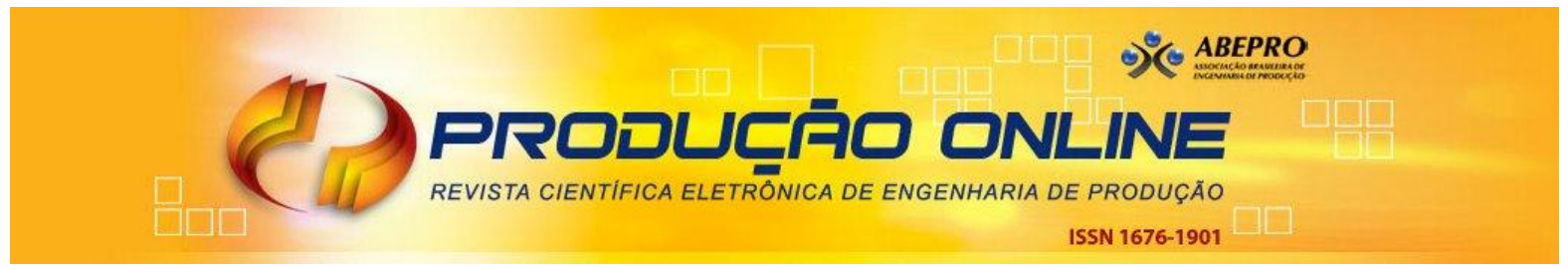

\title{
ANÁLISE DESCRITIVA DE FATORES QUE INFLUENCIAM RESULTADOS ECONÔMICOS NO CLUSTER MOVELEIRO DE BENTO GONÇALVES
}

\section{DESCRIPTIVE ANALYSIS OF FACTORS THAT INFLUENCE ECONOMICAL RESULTS IN THE FURNITURE CLUSTER OF BENTO GONÇALVES}

\author{
Miguel Afonso Sellitto*E-mail: sellitto@unisinos.br \\ João Paulo Rossatto*E-mail: iprossatto@bol.com.br \\ Ismael Luzzi* E-mail: iluzzi@pop.com.br \\ Giancarlo Medeiros Pereira* E-mail: gian@unisinos.br \\ Miriam Borchardt* E-mail: miriamb@unisinos.br \\ *Universidade do Vale do Rio dos Sinos (UNISINOS), São Leopoldo, RS.
}

\begin{abstract}
Resumo: O objetivo deste artigo é analisar fatores que influenciam a competitividade das empresas do cluster moveleiro de Bento Gonçalves, no Rio Grande do Sul. Por revisão bibliográfica, identificaram-se quatro fatores que podem influenciar a competitividade em clusters: produtividade da região, inovação, relação com fornecedores e cooperação entre empresas. O método de pesquisa é o estudo de caso único. As técnicas de pesquisa são a revisão bibliográfica, análise documental específica sobre o cluster estudado e entrevistas com especialistas do cluster. As principais conclusões do estudo foram: o cluster tem alta produtividade, principalmente pela maquinaria de alta tecnologia empregada pelas principais empresas; a inovação é permanente e motivada pela imposição, pelas grandes empresas, de metas às pequenas e médias empresas; a relação com fornecedores oligopolizados é problemática pela pouca existência na região da prática de compras coletivas; e a cooperação entre empresas é pequena, pela cultura arraigada na região de depender pouco de recursos que estão fora das empresas. Tais fatores podem ajudar a construir hipóteses de pesquisa para futuros estudos.
\end{abstract}

Palavras-chave: Clusters. Indústria Moveleira. Cooperação., Desenvolvimento Regional.

Abstract: The purpose of this article is to analyze factors that can influence the competitiveness of companies in the furniture cluster of Bento Gonçalves, Rio Grande do Sul. By a literature review, we identify four factors that can influence competition in clusters: the region's productivity, innovation, relationship with suppliers, and cooperation between companies. The research method is the single case study. The research techniques are the review of specific bibliographic and documentation of the studied cluster, and interviews with experts of the cluster. The main findings are: the cluster has high productivity, mainly by hi-tech machinery employed by the main companies; innovation is permanent and motivated by the imposition to medium and short companies of business goals by the main companies; the relationship with suppliers is problematic regarding the large-scale vendors by the lack of the practice of collective purchases in the area; and cooperation between enterprises is small, by the culture of the region that don't appreciate depending on resources available outside the companies. Such factors can contribute to produce hypotheses for further research.

Keywords: Cluster. Furniture Industry. Cooperation. Regional Development. 


\section{INTRODUÇÃO}

O setor moveleiro da região de Bento Gonçalves, no Rio Grande do Sul, se caracteriza por ter poucas grandes empresas líderes, que competem com sucesso em mercados globais, apoiadas por muitas pequenas e médias empresas locais, fornecedoras de materiais e serviços para as empresas líderes. O setor é intensivo em mão-de-obra e seu valor adicionado por unidade de mão-de-obra é mais baixo do que em outros setores também intensivos, tais como as indústrias da moda e da tecnologia (QUADROS, 2002; SOUZA, 2004; LOPES, 2008).

Nem sempre as novas formas de competição têm sido entendidas e assimiladas por pequenas e médias empresas regionais, como as da região de Bento Gonçalves. Além de redução de custo, a nova competição tem exigido inovação e acesso a novos mercados, o que pode demandar um modelo específico de desenvolvimento regional (BRUNO et al., 2011). As novas habilidades e competências necessárias para operar neste modelo específico podem ser adquiridas por meio das relações de colaboração que surgem entre empresas da mesma região (RODRIGUES; SELLITTO, 2008).

$\mathrm{Na}$ região de Bento Gonçalves, a integração resultante da articulação empresarial e das ações estruturantes das grandes empresas tem gerado uma cultura própria e um comportamento regional similar ao que é descrito na literatura como um cluster, ou seja, tem desenvolvido vantagens para empresas da mesma indústria e região (WILK; FENSTERSEIFER, 2003). Empresas locais têm se organizado em ações de cooperação com outras empresas e com órgãos oficiais, tal como observadas em clusters industriais (CARDOSO; CASAROTTO FILHO, 2011). Lideranças da região referem-se à mesma como o cluster moveleiro de Bento Gonçalves (SOUZA, 2004).

Os termos cluster, distrito industrial e arranjo produtivo local têm sido utilizados para definir aglomerações de empresas com atividades vinculadas, localizadas na mesma região. Carneiro et al. (2007) apresentam um quadro que caracteriza as diferenças entre os termos. Segundo tal quadro, o termo cluster aplica-se a aglomerados em que grandes empresas com alta tecnologia protagonizam processos colaborativos que envolvem pequenas empresas, que são 
beneficiadas por programas promovidos e metas compartilhadas pelas grandes. Esta característica existe no aglomerado moveleiro de Bento Gonçalves.

O objetivo geral deste artigo foi analisar os fatores que podem influenciar resultados no cluster moveleiro da região de Bento Gonçalves. A região foi escolhida por ser um dos polos moveleiros mais importantes e consolidados do país. Os objetivos específicos foram: (i) definir por revisão bibliográfica que fatores podem influenciar resultados de um cluster como o de Bento Gonçalves (foram definidos produtividade, inovação, relação com fornecedores e relações de cooperação entre as empresas); (ii) por revisão bibliográfica, descrever a indústria; e (iii) por pesquisa de campo com especialistas da região, de entidades representativas de classe e gestores de empresas da indústria, estudar a situação destes fatores. O método de pesquisa foi o estudo de caso.

\section{CLUSTERS INDUSTRIAIS}

Uma forma de aumentar a competitividade de empresas de uma indústria localizadas na mesma região é a utilização das vantagens criadas pela proximidade geográfica. Algumas destas vantagens estão ligadas à redução de custos de transação e ao suporte à inovação (OPRIME et al., 2009), resultando em mais competitividade para a região (PETTER et al., 2011). Para tanto, várias empresas participam do negócio dividindo o trabalho, tal como ocorre na produção de calçados, mobiliário ou confecções. Cabe a cada empresa uma parte da atividade: processamento de matérias-primas, fabricação de componentes e de subsistemas, montagem final, serviços de apoio, fabricação de máquinas, distribuição, etc. Tal configuração é conhecida como cluster (CARNEIRO et al., 2007). Embora seja uma palavra estrangeira, o termo cluster tem sido usado na literatura nacional em sua forma original. Uma sugestão de eventual tradução para o termo é aglomerado.

A organização em cluster estimula a formação de grupos de empresas e instituições geograficamente próximas, localizadas em áreas territoriais identificadas e atendendo a um mercado específico (BRUNO et al., 2011). Também compreende clientes, fabricantes de produtos complementares e empresas de tecnologia (PORTER, 2003). O conceito de clusters industriais aborda as vantagens da indústria localizada, materializada em aspectos como: produtividade baseada em 
tecnologia, mão-de-obra especializada e na divisão do trabalho, relação com fornecedores, relações entre as empresas e relações com instituições de apoio e centros de pesquisa tecnológica. O cluster valoriza as culturas locais e regionais e tem inserido pequenas e médias empresas no mercado, gerando desenvolvimento econômico e bem-estar social nas regiões (CROCCO et al., 2003). Seu funcionamento pode assumir comportamento complexo, pois envolve aspectos econômicos, culturais, sociais e ambientais, que interagem entre si e são mutuamente dependentes (CARNEIRO et al., 2007).

Segundo Porter (1998), um cluster é uma concentração geográfica de empresas e instituições correlatas, tais como instituições de pesquisa, universidades e órgãos governamentais, pertencentes a um mesmo setor de atividades. Geralmente, clusters surgem espontaneamente pela ação de empreendedores e, à medida que evoluem e se fortalecem, surgem instituições e mecanismos de suporte e apoio à produção, tais como escolas e entidades de classe (CHIOCHETTA e HATAKEYAMA, 2007). Clusters também podem ser entendidos como uma aglomeração espacial de empresas e fornecedores de matérias-primas e serviços que possuam uma especialização e atuem em um tipo de negócio que as diferencie. Em suma, clusters são agrupamentos de empresas que têm em comum a localização geográfica e a especialização setorial (MYTELKA e FARINELLI, 2000; ALTENBURG e MEYER-STAMER, 1999; SCHMITZ e NADVI, 1999).

Em clusters, podem ser observadas relações de identidade sociocultural, relacionadas a uma origem comum a muitos dos atores envolvidos, como ocorre em zonas de imigração (LINS, 2000). As relações podem ser de negócios ou sócioculturais, podem ser simultaneamente cooperativas e competitivas e podem envolver serviços de apoio às atividades produtivas, comercialização em mercados distantes e incluir redes de instituições públicas e privadas que sustentem as ações dos agentes produtivos (CROCCO et al., 2003). Exemplos clássicos de clusters são o vale do silício e o cluster de vinhos, na Califórnia, lazer e entretenimento em Las Vegas (PORTER, 1998), os clusters calçadistas do vale do Sinos e de Franca e fumageiro do vale do Rio Pardo, no Rio Grande do Sul (SOUZA, 2004).

Clusters têm gerado uma estrutura de relações institucionais locais, que confere vantagens de competição que não são observadas em empresas dispersas geograficamente. Algumas das vantagens observadas são: redução dos custos de 
transporte, de transação e por informação imperfeita; rápida difusão de inovações e assimilação de boas práticas de fabricação; e aumento da divisão do trabalho e da especialização das empresas. Em síntese, clusters apresentam produtividade mais elevada e ambiente mais propenso à inovação, devido às relações que se estabelecem entre as empresas e com os mercados (GARCIA et al., 2004; LOMBARDI, 2003, SUZIGAN et al., 2001; KRUGMAN, 1998; SCOTT, 1998; SONOBE et al., 2006).

Clusters já estabelecidos tem mais probabilidade de atrair entrantes e novas empresas da indústria, pois estas aproveitam as vantagens competitivas já estabelecidas e reduzem a incerteza em operações, tais como localização e desenvolvimento de fornecedores e de mão-de-obra qualificada. Clusters são oportunidades para que uma empresa focal agilize e encurte a sua cadeia de abastecimento, uma vez que as fontes de suprimentos concentram-se em áreas próximas (GILBERT et al., 2008).

Clusters podem ser vistos segundo três características principais: a proximidade física, as competências essenciais e os relacionamentos. Enright (1999) distingue clusters regionais, sugerindo as seguintes dimensões: abrangência geográfica, densidade, largura, profundidade, base de atividade, potencial de crescimento, posição competitiva, a capacidade de inovação, organização industrial e mecanismos de coordenação. Markusen (1996) classifica os clusters baseando-se na área geográfica, nas decisões de investimento privado, na disponibilidade de mão-de-obra e no volume de comércio dentro e fora do cluster.

Markusen (1996) e Porter (1998) citam a alta empregabilidade observada no cluster, o compartilhamento de recursos escassos, e concorrência e cooperação simultâneas como estímulo ao desenvolvimento regional. A inovação e o desenvolvimento de novos produtos e processos também são fatores críticos para a competitividade coletiva de clusters (OPRIME et al., 2009). No caso de pequenas empresas, a falta de capacitação gerencial pode implicar a falta de uma estratégia de produção coordenada com outras empresas, o que pode limitar os ganhos sinérgicos nascidos das complementaridades. Uma alternativa para esta fragilidade é que a formulação de estratégias cooperativas seja coordenada pelas grandes empresas ou por entidades externas (SANTOS e BATALHA, 2010).

Segundo Antonelli (2000), há um crescente consenso de que clusters industriais permitem que pequenas e médias empresas compitam em mercados 
distantes. Quando organizadas em clusters, pequenas empresas podem enfrentar competidores, devido ao compartilhamento de recursos, capacidade de inovação e conhecimento mutuamente adquirido. Segundo Porter (2003), quando as empresas operam em aglomeração, as interações repetidas aumentam a concorrência e melhoram a produtividade e a inovação e constroem confiança. Empresas que operam em um cluster podem ter a vantagem de escala, sem lidar com a inflexibilidade da integração vertical ou outros vínculos formais. Também podem compartilhar informações sobre produto, mercado, design e políticas de comercialização e compartilhar programas de formação de recursos humanos, desenvolvimento de competências, compra, transporte e entrega de matériasprimas, controle de qualidade, instalações para testes, financiamento (garantias coletivas de crédito) e patrocínios (ZHANG e LI, 2008).

A estrutura de relações entre as empresas do cluster pode influenciar 0 processo de inovação. Habilidades complementares presentes em diferentes empresas podem ser reunidas no mesmo projeto, desde que haja relações que sustentem esta reunião. Um modo de promover esta complementariedade são projetos comuns entre empresas da região, geralmente sob comando de um dos protagonistas da indústria (AHUJA, 2000; BALESTRIN et al., 2008).

Akoorie e Ding (2009) identificam duas classes de clusters: aglomerações com foco em inovação e tecnologia e comportamento prevalentemente cooperativo; e aglomerações com foco em redução de custo, não necessariamente cooperativos. Outra tipologia divide os clusters em eficientes e eficazes, cujos objetivos são: aumentar a eficiência em produtos e processo conhecidos; e inventar novos produtos e processos (ZELBST et al., 2010). Bruno et al. (2011) mencionam economia criativa e regiões de criatividade. Neste tipo de aglomeração, a inovação está associada à interação permanente entre empresas produtoras e compradoras. Nesta interação, ambiente, território, cultura e relações sociais desempenham papéis centrais. As regiões podem tornar-se atratores de talentos e geradores de conhecimento, construindo ambiente e infraestrutura estimulante ao aprendizado.

Niu (2010) refere-se a clusters como arranjos industriais que adquirem formato de sistemas, com o objetivo de se adaptarem a mercados em rápida mudança e a novas tecnologias. A estrutura organizacional, a perspectiva de adaptação, a troca de know-how tecnológico, os laços fortes de rede e o capital 
intelectual podem ajudar a explicar o desempenho de empresas em clusters industriais. Desta forma, a aglomeração de empresas do mesmo segmento é capaz de proporcionar à indústria vantagens que surgem pela sinergia gerada no conjunto. Uma estrutura de cluster traz benefícios para o setor como um todo e para as empresas isoladamente, já que em um local geograficamente próximo é possível encontrar diversos agentes econômicos que aumentam a eficiência coletiva do complexo. Saliente-se que as empresas presentes no aglomerado são capazes de estabelecer simultaneamente relações de cooperação e de competição, principalmente porque, em alguns casos, a competição se estabelece não em nível da indústria local, e sim entre diferentes indústrias.

Da revisão, depreende-se que alguns elementos estão presentes em estudos de competitividade em clusters. São eles: produtividade da região, descrita por Porter (1998), Antonelli (2000) e Zhang e Li (2008); processo de inovação, descrito por Bruno et al. (2011); relação com fornecedores, descritas por Crocco et al. (2003) e Mytelka e Farinelli (2000); e relações de cooperação entre as empresas, descritas por Oprime et al. (2009) e por Niu (2010). Em análise prévia com os especialistas da MOVERGS que foram entrevistados na fase de campo da pesquisa, este confirmaram que os quatro fatores estão presentes e influenciaram na trajetória do cluster moveleiro. Tal estrutura não esgota os fatores de competição em clusters, mas delimita aqueles pesquisados neste artigo.

A estrutura apontada pode ser comparada com estruturas usadas em outros estudos. Albino et al. (2011), em pesquisa similar no polo moveleiro de Ubá, Minas Gerais, associaram à competitividade do arranjo os seguintes fatores: infra-estrutura, recursos humanos, tecnologia, e aquisições. Gorini (1998), em estudo encomendado pelo BNDES (Banco Nacional de Desenvolvimento Econômico), apontou como fatores de competitividade: matérias-primas, tecnologia, mão-de-obra e design. Leão e Naveiro (2009) apontam: modernização da maquinaria, matérias-primas, cooperação e design. Existem semelhanças entre os conjuntos de fatores de competição. 


\section{A PESQUISA}

A pesquisa é um estudo qualitativo do tipo descritivo. O método de pesquisa foi o estudo de caso (YIN, 2005). As fontes de evidência incluíram pesquisas bibliográficas sobre a indústria e entrevistas em profundidade com especialistas. O método de trabalho foi: (i) consulta a dados do SINDMÓVEIS (Sindicato das Indústrias do Mobiliário de Bento Gonçalves); (ii) entrevista com dois executivos da Associação das Indústrias de Móveis do Estado do Rio Grande do Sul (MOVERGS); (iii) entrevista com dois especialistas praticantes, ou seja, especialistas da indústria que exercem atividades de gestão em grandes empresas da indústria moveleira local; (iv) entrevista com dois fornecedores de insumos; (v) entrevista com um pesquisador acadêmico cuja linha de pesquisa inclui as atividades das empresas moveleiras de Bento Gonçalves; e (vi) organização e validação dos resultados com todos os entrevistados. As entrevistas usaram roteiro semiestruturado baseado nos quatro fatores de competitividade revisados. Cada entrevista durou até uma hora.

Inicia-se com uma caracterização geral da indústria moveleira e em particular do cluster de Bento Gonçalves. Esta caracterização foi construída a partir de revisão de bibliografia apontada pelas entidades do setor e de dados destas entidades. Depois passa-se à análise dos fatores investigados. Nas sessões, apontou(aram)-se a(s) entrevista(s) que originou(aram) as informações apresentadas.

\subsection{Indústria moveleira e o cluster de Bento Gonçalves}

A indústria de móveis abastece-se de cadeias produtivas de matérias-primas, tais como madeira, plástico, metais e aglomerados, e fornece produtos para o varejo. A demanda por móveis e artigos de mobiliário é altamente segmentada e tem variado positivamente com o nível de renda da população e com o comportamento de outros setores, particularmente a construção civil. $O$ gasto das famílias com móveis situa-se entre 1\% e $2 \%$ da renda disponível. Outros fatores que influenciam a demanda são as mudanças no estilo de vida, aspectos culturais, ciclo de reposição e investimento em marketing, em geral inferiores ao que é praticado em outras indústrias (LOPES, 2008). 
O IBGE (Instituto Brasileiro de Geografia e Estatística) classifica a indústria de móveis pelas matérias-primas predominantes: madeira, metal, plástico e artefatos de complemento, tais como colchoaria e persianas. A indústria de móveis também é segmentada segundo o uso: residencial ou empresarial. Por fim, a indústria também é segmentada pelo tipo de produto: retilíneo ou torneado (GORINI, 1998).

No Brasil, existem quase 15 mil empresas moveleiras, com cerca de $260 \mathrm{mil}$ empregados. No Rio Grande do Sul (RS) são cerca de 2.370 empresas, com cerca de 40,8 mil empregados. Em Bento Gonçalves, são 370 empresas, com 10,5 mil empregados. A indústria moveleira é a principal atividade econômica do município. Em 2011, 71\% do Produto Interno Bruto gerado pelo município foi oriundo deste setor (SINDMÓVEIS, 2012). Quanto às empresas, $85 \%$ produzem móveis de madeira, $9 \%$ móveis de metal, cerca de $5 \%$ móveis estofados e $1 \%$ outros móveis. No RS, o setor é composto principalmente por pequenas e médias empresas: cerca de $42 \%$ faturam até $R \$ 600$ mil/mês; $16 \%$ faturam de $R \$ 601$ mil a $R \$ 1,2$ milhões; $32 \%$ faturam de $R \$ 1,2$ a $R \$ 5,0$ milhões e apenas $10 \%$ faturam acima de $R \$ 5,0$ milhões/mês (ABIMÓVEL, 2012). Os principais destinos das exportações foram Estados Unidos, Chile, Argentina e França As vendas para o mercado norteamericano correspondem a mais de $40 \%$ do total do polo de Bento Gonçalves, em parte em razão de um centro de distribuição que as empresas da região construíram nos Estados Unidos (SINDMÓVEIS, 2013). A Tabela 1 sintetiza os dados.

Tabela 1 - Representatividade do cluster de Bento Gonçalves em 2013

\begin{tabular}{llll}
\hline & Brasil & Rio Grande do Sul & Bento Gonçalves \\
\hline Empresas & 17,5 mil & 2,5 mil & 300 \\
Empregos Diretos & 248 mil & 42,8 mil & 9,1 mil \\
Faturamento do Setor & $\begin{array}{l}\mathrm{R} \$ 44,45 \\
\text { bilhões }\end{array}$ & $\begin{array}{l}\mathrm{R} \$ 7,39 \\
\text { bilhões }\end{array}$ & $\begin{array}{l}\mathrm{R} \$ 2,48 \\
\text { bilhões }\end{array}$ \\
Exportações do Setor & $\begin{array}{l}\text { U } \$ 703 \\
\text { milhões }\end{array}$ & $\begin{array}{l}\text { U } \$ 211 \\
\text { milhões }\end{array}$ & $\begin{array}{l}\text { U } \$ 58,3 \\
\text { milhões }\end{array}$ \\
& $\begin{array}{l}\text { ABIMÓVEL } \\
\text { SECEX (Secretaria de }\end{array}$ & $\begin{array}{l}\text { MOVERGS } \\
\text { SECEX }\end{array}$ & $\begin{array}{l}\text { SINDMOVEIS } \\
\text { SECEX/ SEFAZ } \\
\text { (Secretaria da }\end{array}$ \\
& Comércio Exterior) & & Fazenda) \\
\hline
\end{tabular}

Fonte: SINDMÓVEIS (2013) 
A produção nacional de móveis concentra-se, principalmente, em polos regionais: Grande São Paulo (SP), Bento Gonçalves (RS), São Bento do Sul (SC), Arapongas (PR), Ubá (MG), Mirassol (SP), Votuporanga (SP) e Linhares (ES) (SILVA e SANTOS, 2005).

O surgimento da indústria moveleira no Rio Grande do sul tem origens históricas, remontando à chegada de imigrantes italianos e alemães que criaram pequenas marcenarias e oficinas de reparos de mobiliário na região. A indústria inclui os munícipios de Antônio Prado, Flores da Cunha, Garibaldi, São Marcos, Caxias do Sul e Bento Gonçalves. Este último município tem a maior concentração de empresas moveleiras da região e por isto passou a ser considerado como sede de um eventual cluster moveleiro na região (ALIEVI e VARGAS, 2002).

A aglomeração representa aproximadamente $80 \%$ do faturamento setorial estadual, sendo que apenas o município de Bento Gonçalves é responsável por metade das vendas totais da indústria moveleira do Rio Grande do Sul. O cluster de Bento Gonçalves é constituído na sua grande maioria (96\%) por micro e pequenas empresas locais. O restante são empresas de médio e grande porte. A governança do cluster, aqui entendida como a organização, direção e controle das ações do setor, está centralizada na Associação das Indústrias de Móveis do Estado do Rio Grande do Sul (MOVERGS), que mobiliza os demais parceiros e procura estabelecer uma agenda de discussão coletiva dos problemas do setor. O cluster de Bento Gonçalves é especializado na produção de móveis modulares, utilizando como matéria-prima principal o MDF (fibra de média densidade), o MDP (partícula de média densidade) e a chapa dura. Em menor escala, dedica-se, também, à fabricação de móveis de pinus e móveis tubulares metálicos (SINDMOVEIS, 2012).

O processo de articulação do setor começou a ser formalizado no ano de 2000, com a implementação do programa Redes de Cooperação da Secretaria de Desenvolvimento e dos Assuntos Internacionais (SEDAI). Em 2001 iniciou o projeto de promoção e desenvolvimento de clusters pela SEDAI, juntamente com a MOVERGS. O primeiro passo foi a identificação da cadeia, dos atores e dos gargalos do setor em diagnóstico realizado pela Universidade Federal do Rio Grande do Sul (UFRGS). A história do cluster foi relatada na entrevista com os dois especialistas da MOVERGS. 
Conforme informações obtidas no Sistema Integrado de Gestão Orientada por Resultados do SEBRAE-RS (SIGEOR), entre os principais parceiros do cluster moveleiro destacam-se a MOVERGS, o Sindicato das Indústrias do Mobiliário de Bento Gonçalves (SINDMÓVEIS), o Serviço Nacional de Aprendizagem Industrial (SENAI), o Centro Tecnológico do Mobiliário (CETEMO/SENAI), o SEBRAE, a Agência de Promoção de Exportação e Investimento (APEX) Brasil, a Universidade de Caxias do Sul (UCS) - Campus da Região dos Vinhedos, a Associação Gaúcha de Empresas Florestais (AGEFLOR), a SEDAI, o Serviço Nacional de Aprendizagem Comercial (SENAC), o Sindicato das Indústrias de Marcenarias, Serrarias, Carpintarias e Tanoarias de Caxias do Sul (SINDMADEIRA) e a Associação das Empresas de Pequeno Porte da Região Nordeste do Rio Grande do Sul (MICROEMPA) (SIGEOR, 2012).

\subsection{Produtividade}

As informações desta sessão foram obtidas principalmente na entrevista com os dois especialistas da MOVERGS (ambos com formação em Administração e com cargos de analistas de produção na entidade) e na entrevista com o pesquisador acadêmico (com formação de doutor em engenharia de produção e cargo de professor e pesquisador em universidade da região).

A produtividade do cluster moveleiro de Bento Gonçalves avançou a partir de 1990, principalmente pela compra de maquinaria importada com tecnologia incorporada. O nível de produtividade atingido possibilitou aumento nas exportações a partir de meados da década de 1990. O número de empresas exportadoras passou de cerca de 50 em 1998, para mais de 300 em 2011. Este acréscimo de produtividade incluiu o fortalecimento de toda a cadeia industrial, desde a produção de madeira até a fabricação final do móvel. A concentração de parte relevante da cadeia produtiva de móveis na região de Bento Gonçalves contribuiu para o aumento de produtividade pela redução de custos de transação.

O aumento da produtividade local deveu-se a diversos fatores, tais como 0 desenvolvimento local de insumos específicos, a geração de mão-de-obra qualificada, o acesso coletivo a informações, o suporte das entidades do setor e os avanços tecnológicos observados nas empresas da região. 
$O$ desenvolvimento de insumos e qualificação de pessoas ocorre em parte devido ao SENAI/CETEMO. A entidade forma e qualifica a mão-de-obra da região para atuação na indústria. O Campus da Região dos Vinhedos da Universidade de Caxias do Sul (UCS) também tem contribuído, com seus cursos superiores de Tecnologia em Produção Moveleira, Desenvolvimento de Produto, Engenharia da Produção, Gestão Empresarial (especialização) e Design Industrial (especialização).

O acesso à informação no cluster se dá por programas desenvolvidos para fornecer informações estratégicas para as empresas, tais como: observatório econômico, observatório de mercado e observatório tecnológico, todos abrigados no Centro Gestor de Inovação (CGI Moveleiro); o SIGEOR do SEBRAE; sites dos parceiros que dispõe de informações especializadas do setor como, MOVERGS, SINDMÓVEIS, SEBRAE, entre outros.

Quanto à tecnologia, houve introdução de equipamentos automatizados que contribuíram para o aumento da produtividade e para a flexibilização dos processos produtivos, ou seja, a mesma linha de produção pode oferecer muitos tipos de produto. A maioria das médias e grandes empresas possui máquinas automatizadas, equipados com CNC (controladores numéricos computadorizados). Aumentou a escala de produção da indústria, com redução de custo. Os fornecedores de equipamentos são predominantemente nacionais para linhas nãointegradas e europeus para as integradas, principalmente da Alemanha e da Itália. $O$ cluster afeta a produtividade de outras indústrias da região, pois estimula a presença local de fornecedores internacionais de maquinaria avançada e serviços correlatos.

Uma crítica recorrente no setor é que o governo, trabalhando em conjunto com o setor privado, poderia e deveria reforçar a estrutura estratégica e trabalhar em clusters emergentes ou já existentes, ao invés de tentar criar arranjos inteiramente novos, tais como tenta fazer com alguns arranjos produtivos locais (APL).

\subsection{Inovação}

As informações desta sessão foram obtidas principalmente na entrevista com os dois especialistas da MOVERGS, com formações já citadas.

O fortalecimento que a organização em cluster tem proporcionado para a capacidade inovativa das empresas da região pode ser sintetizado por algumas 
características que aumentaram os níveis de produtividade, tais como: mais clareza nas novas necessidades dos compradores; mais rapidez nas decisões de compra (se comparada a competidores isolados); maior discernimento sobre tendências de compradores de mobiliário; mais rápida percepção de novas possibilidades tecnológicas, operacionais ou de distribuição; e possibilidade de realizar experimentos e pesquisas a custos mais reduzidos. O processo no cluster tem considerado a inovação organizacional a partir de dois pontos-chave: a aprendizagem organizacional; e a cooperação interorganizacional. Ambas, integradas, tem levado à capacitação da mão-de-obra e das empresas.

A inovação ocorre a partir de um processo de interação entre os agentes do cluster (empresas, instituições e governo). Para isto, contribuem a difusão dos conhecimentos e a capacitação de atores. O cluster implementou o CGI (Centro Gestor de Inovação Moveleiro) para capacitar empresários e gestores para a inovação e fortalecer a capacidade inovativa das empresas.

O sistema local de inovação existente foi estruturado e aprimorado a partir das demandas percebidas e apontadas pelo cluster. Esta infraestrutura de suporte é usada pelas empresas, aproveitando as oportunidades de inovação que são oferecidas. Muitas empresas utilizam a relação com o cliente, materializada em demandas inovativas, e a participação em feiras e em congressos como fontes de informações e aprendizado.

O sistema local de inovação é formado por:

- CGI Moveleiro: Objetiva contribuir para a modernização industrial, por meio do apoio a inovações técnicas e tecnológicas voltadas às empresas do setor moveleiro, com ênfase na utilização da infra-estrutura laboratorial instalada na região;

- SENAI/CETEMO: Presta serviços de formação técnica, assessoria técnica, serviços laboratoriais, operacionais e faz pesquisa aplicada;

- Incubadora Tecnológica Moveleira (SENAI/INCMOVEL): Objetiva apoiar legal e gerencialmente a constituição de empresas de base tecnológica voltadas ao atendimento das demandas do setor; e

- Programa Via Design: Objetiva elevar a competitividade dos produtos e promover as exportações de pequenas e médias empresas por meio de desenvolvimento no design dos produtos. 
A aglomeração tem levado ao surgimento de práticas entre empresas que tem estimulado a capacidade inovativa. Foram observados dois tipos de inovação: a revolucionária, que altera substancialmente o produto ou o processo produtivo, inaugurando uma nova etapa no negócio, principalmente nas empresas líderes; e a incremental, que proporciona pequenas e permanentes melhorias em produtos e processos existentes, principalmente nas médias e pequenas fornecedoras. Nestas últimas, a inovação surge principalmente para atender demandas das grandes empresas em seus esforços para atingir novos mercados.

Para algumas das grandes empresas, a inovação de produtos e processos é fator determinante para o sucesso de seus negócios. Com isto, exigem de seus fornecedores novos processos ou novas formas de organizar a produção, a maioria das vezes para atingir níveis de custo e qualidade exigidos pelo mercado das grandes. Pela proximidade geográfica, outros membros do cluster são influenciados, mesmo sem ter envolvimento direto com processos inovativos. Este efeito é materializado principalmente nas exigências de desempenho que se propagam no cluster; pelas exigências da mão-de-obra; e pela oferta de novos materiais, procedimentos, serviços e soluções tecnológicas.

\subsection{Relação com fornecedores}

As informações desta sessão foram obtidas principalmente na entrevista com os dois especialistas praticantes de grandes empresas (um com formação em engenharia de produção, outro em engenharia mecânica, ambos em cargos de gerente de projeto) e na entrevista com dois fornecedores de insumos (ambos com formação técnica em mobiliário e cargos de gerente de produção).

A principal dificuldade enfrentada pelas empresas do cluster no relacionamento com os fornecedores é de ter que lidar com os produtores de chapas de MDP e MDF, representados pela Associação Brasileira da Indústria de Painéis de Madeiras (ABIPA).

Devido às restrições impostas pelas atuais políticas e práticas ambientais, 0 uso de madeira nobre natural foi contingenciado. Aumentou a necessidade dos compradores por materiais alternativos e por consequência o poder de negociação dos produtores de chapas. A entidade defende os interesses dos produtores e atua 
quase como um cartel, impondo preços aos compradores. Nas entrevistas, constatou-se que a dependência dos grandes fornecedores em relação às compras feitas por empresas do cluster moveleiro de Bento Gonçalves, é baixa ou no máximo média. Portanto, apesar do potencial ganho de escala que a aglomeração de empresas poderia criar, o volume de compras unificadas ainda é pequeno a ponto de poder influenciar o mercado fornecedor. Como muitas grandes empresas da região concorrem entre si pelo mercado comprador de móveis, ainda há dificuldades em organizar compras coletivas.

Em contrapartida, o cluster moveleiro é dependente destes fornecedores. Como suas vendas são dispersas geograficamente, a capacidade de compra do cluster não é suficientemente significativa a ponto de criar ou ao menos alavancar algum poder de barganha. Verifica-se uma assimetria: o cluster depende mais dos fornecedores do que os fornecedores do cluster. Logo, os relacionamentos estratégicos com esses fornecedores são limitados, ficando o cluster com pouco poder para impor condições aos fornecedores. Esta dificuldade parece relevante e os especialistas consultados não se mostraram otimistas quanto à possibilidade de mudança em curto prazo. Uma linha de pesquisa tem sido desenvolvida em algumas empresas no sentido de depender menos de matérias-primas de difícil acesso, mas esta linha ainda não se mostrou suficientemente promissora.

Considerando o poder econômico dos fabricantes de MDP e MDF, é possível que os fabricantes de móveis sejam um elo fraco na cadeia produtiva de madeira e móveis. Ainda não existem dados no setor que apontem para o fortalecimento de relações de parceria entre fornecedores e compradores.

Para diminuir as distâncias internas observadas na cadeia de suprimentos, as entidades representativas do setor conseguiram a vinda de uma fábrica de painéis de MDF e MDP para o estado. Em 2000, o Grupo Isdra construiu a fábrica Fibraplac em Glorinha, a cerca de 120 quilômetros de Bento Gonçalves. Em 2009, a Masisa Brasil instalou uma planta fabril de MDF e MDP em Montenegro, a 80 quilômetros de Bento Gonçalves. Apesar da importância da ação do governo estadual na atração das duas empresas, os entrevistados consideram que a pressão feita pela vinda das fábricas foi atendida pela alta representatividade das entidades ligadas ao cluster. 


\subsection{Cooperação}

As informações desta sessão foram obtidas principalmente na entrevista com os dois especialistas praticantes de grandes empresas, com formações já citadas.

As empresas do cluster de Bento Gonçalves têm enfrentado dificuldades para estabelecer e praticar relações de cooperação. Faz parte da cultura empresarial da região depender menos de recursos alocados fora das respectivas empresas. Por muito tempo, as grandes empresas fabricaram o móvel inteiro, sem terceirizar componentes, justamente para depender menos de recursos externos. Foi somente após o ano 2000 que as grandes empresas começaram a terceirizar partes relevantes do móvel, devido aos processos produtivos terem ficado mais complexos. Pela divisão do trabalho baseada na cooperação e pela especialização desenvolvida nas pequenas e médias empresas, foi aumentada a eficiência da região. A partir de então, pequenas e médias empresas do cluster foram subcontradas por empresas maiores, passando a operar como fornecedores de componentes. Tais experiências, porém, não caracterizam difusão na cultura de cooperação no cluster. Segundo os entrevistados, ainda existem menos trocas cooperativas do que seria desejável, principalmente em sistemas de informação, desenvolvimento e transferência de tecnologia ou em ações de fortalecimento de empresas.

Mesmo que o cluster conte com instituições (MOVERGS, SINDMOVEIS, SENAI/CETEMO) cujos objetivos incluem o fortalecimento da aglomeração produtiva, os ganhos mútuos ainda têm ficado abaixo do máximo possível. Ainda observa-se resistência entre as empresas quanto ao estabelecimento de vínculos mais estreitos na cadeia produtiva, tanto horizontais quanto verticais. Por exemplo, os principais ganhos advindos da inovação são originados de metas impostas às empresas, não de processos gerenciados de cooperação.

Mesmo que já tenha sido observado algum aumento da cooperação no cluster, a forma que tem sido mais observada é a de curto prazo. Tal forma impõe soluções puntuais para problemas específicos, tais como: embates políticos para isenção de impostos; busca de incentivo a linhas de crédito e benefícios para exportação; redução do custo de energia elétrica ou benefícios para uso de energias renováveis; e outras demandas em relação a governos. Entre as empresas de grande porte, percebe-se pouca cooperação e é baixa a probabilidade que surjam 
alianças estratégicas mais estreitas para obtenção de vantagens competitivas mais significativas, ligadas, por exemplo, a aumento de produtividade global, racionalização no uso de recursos ou aumento do poder de barganha com fornecedores. O principal objetivo de cada uma é aumentar sua fatia de mercado, caracterizando, simultaneamente, cooperação e competição.

Por fim, a principal dificuldade na adoção de comportamentos cooperativos mais intensos tem sido a dificuldade em agrupar os interesses e a falta de diálogo. $\mathrm{O}$ que se percebe é que, geralmente, as grandes empresas, tendo maior capacidade de compra, de produção e de venda, têm demonstrado pouco interesse na viabilização de relações cooperativas mais intensas com as pequenas e médias. No longo prazo, tal aversão à cooperação pode acarretar prejuízos competitivos inclusive para as próprias grandes empresas, pois, segundo os entrevistados, mais cooperação viria ao encontro dos interesses do cluster e da região como um todo.

\subsection{Síntese}

O Quadro 1 sintetiza os achados e descreve os quatro fatores estudados, com considerações da revisão e das entrevistas. Observa-se que o resultado global dos dois primeiros fatores é positivo, enquanto que os dois últimos representam oportunidades que ainda não foram exploradas na sua integralidade pelo cluster. 
Quadro 1 - Síntese de achados, descrição dos fatores e comparação com a revisão

\begin{tabular}{|c|c|c|}
\hline $\begin{array}{c}\text { Fator } \\
\text { estudado }\end{array}$ & Revisão & Situação observada no cluster \\
\hline Produtividade & $\begin{array}{l}\text { A redução de distâncias, o } \\
\text { ganho de escala, a } \\
\text { especialização e a qualificação } \\
\text { da mão-de-obra são geradoras } \\
\text { de vantagem. }\end{array}$ & $\begin{array}{l}\text { A produtividade observada no cluster é elevada } \\
\text { em relação a outras indústrias da região e à } \\
\text { indústria moveleira de outras regiões. Os } \\
\text { principais fatores são o baixo custo de } \\
\text { desenvolvimento e de alguns fornecimentos, a } \\
\text { abundância de mão-de-obra qualificada e a } \\
\text { tecnologia instalada a partir de } 2000 \text {. Todos } \\
\text { estes fatores se originaram da ação de cluster } \\
\text { observada na região. }\end{array}$ \\
\hline Inovação & $\begin{array}{l}\text { A inovação é decorrência de } \\
\text { processos de aprendizado e } \\
\text { capacitação. }\end{array}$ & $\begin{array}{l}\text { Existem múltiplas e fortes instituições no cluster } \\
\text { que agem como capacitadoras de mão-de-obra } \\
\text { e de empresas. O papel destas instituições é } \\
\text { reconhecido como estimulador da inovação no } \\
\text { cluster. A inovação é reconhecida como intensa } \\
\text { e é responsável por vantagens competitivas } \\
\text { construídas no cluster, mas é formada } \\
\text { principalmente pela imposição de metas às } \\
\text { pequenas e médias pelas grandes. }\end{array}$ \\
\hline $\begin{array}{l}\text { Relação com } \\
\text { fornecedores }\end{array}$ & $\begin{array}{l}\text { Formações empresariais } \\
\text { aglomeradas podem impor } \\
\text { condições favoráveis de } \\
\text { negociação e construir } \\
\text { vantagem competitiva. }\end{array}$ & $\begin{array}{l}\text { O cluster estudado não tem escala suficiente } \\
\text { para impor melhores condições comerciais a } \\
\text { alguns fornecedores oligopolizados. É } \\
\text { necessário aprofundar as relações entre as } \\
\text { empresas com vistas a aumentar de modo } \\
\text { significativo o ganho de escala ou ao menos } \\
\text { modificar o produto de forma a depender menos } \\
\text { dos fornecedores oligopolizados. Atualmente, } \\
\text { há dificuldade em usufruir de mais ganhos de } \\
\text { escala no abastecimento industrial. }\end{array}$ \\
\hline Cooperação & $\begin{array}{l}\text { A proximidade geográfica e } \\
\text { sócio-cultural facilita e estimula } \\
\text { a criação de relações de } \\
\text { cooperação entre empresa, } \\
\text { dentro e fora do ambiente } \\
\text { empresarial. }\end{array}$ & $\begin{array}{l}\text { As relações de cooperação são prejudicadas } \\
\text { por posturas tradicionalmente adotadas por } \\
\text { empresários, de depender pouco de recursos } \\
\text { pertencentes a outras empresas. De modo } \\
\text { geral, as empresas preferem manter a } \\
\text { autossuficiência. }\end{array}$ \\
\hline
\end{tabular}

\section{CONCLUSÕES}

Neste artigo, foram analisados descritivamente quatro fatores que podem influenciar a competitividade das empresas do cluster moveleiro da região de Bento Gonçalves: produtividade, inovação, relação com fornecedores, e relações de cooperação entre empresas. As principais conclusões do estudo foram: os dois primeiros fatores parecem definidos e consolidados e os dois últimos apresentam dificuldades.

As entrevistas apontaram que o cluster moveleiro de Bento Gonçalves tem aumentado sua produtividade e promovido a inovação, gerando influência sobre outros municípios e outras indústrias da região. Também apontaram que o cluster 
apresenta deficiências que reduzem a competitividade das empresas e da região, principalmente quanto à dependência de fornecedores oligopolizados e nas relações de cooperação entre as empresas.

Segundo os dados do SINDMÓVEIS e as informações dos entrevistados da MOVERGS e do pesquisador acadêmico, a produtividade da indústria na região é mais elevada do que a de outras indústrias da região e de indústrias moveleiras de outras regiões. Segundo as informações dos entrevistados da MOVERGS, existe uma rede articulada de entidades que promovem a inovação e existe bastante inovação no cluster, mas esta é motivada principalmente pela imposição de metas pelo mercado às grandes empresas, que as repassam às demais. Segundo as informações dos entrevistados das grandes empresas e dos fornecedores, a relação com fornecedores oligopolizados não é favorável ao cluster: a interação entre as empresas não é suficiente para gerar uma escala de compras coletivas que garanta melhores condições de barganha para os compradores. Por fim, segundo as informações dos entrevistados das grandes empresas, a cooperação é menos intensa do que seria possível, principalmente devido à cultura enraizada no cluster de depender pouco de terceiros.

Como contribuições ao setor e à região apontam-se alternativas que podem ser exploradas em futuras pesquisas e futuras ações de melhoria. Dentre as oportunidades que o cluster oferece e que têm sido pouco exploradas são: tecnologia conjunta de desenvolvimento de produto com apoio de sistemas informatizados (e-collaboration), unificação de operações logísticas de entrada de insumos, armazenamento de produtos acabados e movimentação e abastecimento interno (uso de operador logístico coletivo), e adoção conjunta de programas de formação de mão-de-obra para futura aplicação de métodos mais avançados de gestão da produção (manufatura enxuta, produção mais limpa, etc.).

Tecnologias mais avançadas de projeto de desenvolvimento de produto poderiam envolver compra conjunta de sistemas CAD-CAE-CAM, incluindo também as pequenas empresas fornecedoras de peças e serviços. Unificação de atividades logísticas poderia incluir a contratação coletiva ou a busca coletiva pela instalação de um operador logístico de grande porte na região, de modo que muitas empresas pudessem integrar suas operações logísticas, aproveitando as vantagens que a abordagem da cadeia de suprimentos pode oferecer. Por fim, quanto a métodos 
mais avançados de gestão, as empresas poderiam montar, em conjunto com as entidades de ensino e pesquisa, programas permanentes de formação gerencial de mão-de-obra, haja vista que a maior parte dos programas existentes trata muito mais de aspectos técnicos e operacionais dos processos produtivos e muito menos dos aspectos estratégicos e gerenciais da atividade.

Um problema potencial relevante parece ser a pouca noção estratégica que muitas empresas da região têm do potencial para a construção de vantagem competitiva que a aglomeração oferece. Muitas das deficiências e oportunidades apontadas poderiam ser eliminadas ou aproveitadas, e metas mais ousadas poderiam ser alcançadas, se as empresas da região enfrentassem os problemas coletivamente, criando ações conjuntas para fortalecer o cluster.

\section{RECONHECIMENTO}

Agradece-se às empresas, às entidades de classe e aos executivos que colaboraram para a realização da pesquisa. Também agradece-se ao CNPq por financiar parcialmente esta pesquisa.

\section{REFERÊNCIAS}

ABIMÓVEL. Associação Brasileira das Indústrias do Mobiliário. Dados do Setor. Brasil: 2012. Disponível em: <http://www.abimovel.com>. Acesso em: 20 nov. 2012.

AHUJA, G. Collaboration networks, structural holes, and innovation: a longitudinal study, Administrative Science Quarterly, v.45, n.3, p.425-55, 2000. http://dx.doi.org/10.2307/2667105

AKOORIE, M.; DING, Q. Global competitiveness in the Datang hosiery cluster, Zhejiang, Chinese Management Studies, v.3, n.2, p.102-116, 2009. http://dx.doi.org/10.1108/17506140910963611

ALBINO, A.; SOUZA, S.; LIMA, A.; ALMEIDA, M.; BEHR, R. Aplicação do modelo analítico da cadeia de valor na análise da estratificação competitiva em um APL. Produção Online, v.11, n.1, p.263-287, 2011. http://dx.doi.org/10.14488/16761901.v11i1.856

ALIEVI, R.; VARGAS, M. Capacitação tecnológica e inovação no arranjo produtivo moveleiro da serra gaúcha. In: CASTILHOS, C. (org.) Programa de Apoio aos 
Sistemas Locais de Produção: a construção de uma política pública no RS. Porto Alegre: FEE; SEDAI, 2002.

ALTENBURG, T.; MEYER-STAMER, J. How to Promote Clusters: Policy Experiences from. Latin America. World Development, v.27, n.9, p.1693-1713, 1999. http://dx.doi.org/10.1016/S0305-750X(99)00081-9

ANTONELLI, C. Collective Knowledge Communication and Innovation: The Evidence of Technological Districts. Regional Studies, v.34, n.6, p.535-547, 2000. http://dx.doi.org/10.1080/00343400050085657

BALESTRIN, A.; VARGAS, L.; FAYARD, P. Knowledge creation in small firm network. Journal of Knowledge Management, v.12, n.2, p.94-106, 2008. http://dx.doi.org/10.1108/13673270810859541

BRUNO, F.; NETTO, H.; BRUNO, A. Aspectos impulsionadores do potencial inovador da indústria têxtil e de confecção no distrito criativo de Flandres: inspirações para a formulação de políticas no Brasil. Produção Online, v.11, n.4, p.1028-1058, 2011. http://dx.doi.org/10.14488/1676-1901.v11i4.713

CARDOSO. J; CASAROTTO FILHO, N. A estrutura intelectual de investigação de aglomerações produtivas: um estudo no âmbito da ABEPRO. Produção Online, v.11, n.3, p.871-890, 2011. http://dx.doi.org/10.14488/1676-1901.v11i3.1007

CARNEIRO, C.; ZORZAL, E.; SANTOS, G.; BASTOS, M. NUNES, R. A redução dos custos no uso de arranjos produtivos locais na gestão competitiva da logística de suprimentos: estudo de caso no APL Leite \& Sol da cadeia produtiva do leite no estado do Ceará. Produção Online, v.7, n.4, ed. esp., 2007.

http://dx.doi.org/10.14488/1676-1901.v7i4.60

CHIOCHETTA, J.; HATAKEYAMA, K. Implementação de um APL - arranjo produtivo local - o caso do setor metal mecânico da região sudoeste do estado do Paraná.

Produção Online, v.7, n.1, p.58-70, 2007. http://dx.doi.org/10.14488/1676-

1901.v7i1.96

CROCCO, M.; SANTOS, F.; SIMÕES, R.; HORÁCIO, F. Industrialização descentralizada: sistemas industriais locais. $\mathrm{O}$ arranjo produtivo calçadista de Nova Serrana (MG). Parcerias Estratégicas, v.17, p.55-14, 2003.

ENRIGHT, M. The globalization of competition and the localization of competitive advantage: policies toward regional clustering, in HOOD, N.; YOUNG, S. (org.), The Globalization of Multinational Enterprise Activity and Economic Development. London: Macmillan, 1999.

GARCIA, R., MOTTA, F. G., AMATO NETO, J. Uma análise das características da estrutura de governança em sistemas locais de produção e suas relações com a cadeia global. Gestão \& Produção, v.11, n.3, p.343-354, 2004.

http://dx.doi.org/10.1590/S0104-530X2004000300008 
GILBERT, B.; MCDOUGALL, P.; AUDRETSCH, D. Clusters, knowledge spillovers and new venture performance: an empirical examination, Journal of Business Venturing, v.23, n.4, p.405-22, 2008. http://dx.doi.org/10.1016/i.jbusvent.2007.04.003

GORINI, A. Panorama do setor moveleiro no Brasil, com ênfase na competitividade externa a partir do desenvolvimento da cadeia industrial de produtos sólidos de madeira. BNDES, 1998. Disponível em:

$<$ http://www.bndes.gov.br/SiteBNDES/export/sites/default/bndes pt/Galerias/Arquivo s/conhecimento/bnset/set801.pdf>. Acesso em: 2/06/2012.

KRUGMAN, P. What's new about the New Economic Geography? Oxford Review of Economic Policy, Oxford, v.14, n.2, p.7-17, 1998.

http://dx.doi.org/10.1093/oxrep/14.2.7

LINS, H. Clusters Industriais, competitividade e desenvolvimento regional: da experiência à necessidade de promoção. Estudos Econômicos, v.30, n.2, p.233265, 2000.

LEÃO, M.; NAVEIRO, R. Fatores de competitividade da indústria de móveis de madeira do Brasil. Revista da Madeira, v.119, agosto de 2009.

LOMBARDI, M. The Evolution of Local Production Systems: the emergence of the "invisible mind" and the evolutionary pressures towards more visible "minds".

Research Policy, v.32, n.9, p.1443-1462, 2003. http://dx.doi.org/10.1016/S00487333(02)00157-9

LOPES, M. O processo inovativo e o papel das instituições no arranjo produtivo de móveis da serra gaúcha. Dissertação de Mestrado em Economia. UNISINOS, São Leopoldo: 2008.

MARKUSEN, A. Sticky places in slippery space: a typology of industrial districts. Economic Geography, v.72, n.3, p.293-313, 1996. http://dx.doi.org/10.2307/144402

MOVERGS - Dados do Setor Moveleiro. Associação das Indústrias de Móveis do Estado do Rio Grande do Sul, Bento Gonçalves, RS, Brasil, 2012. Disponível em <http://www.movergs.com.br/numeros-setor>. Acesso em: novembro de 2012.

MYTELKA, L.; FARINELLI, F. Local clusters, innovation and sustained competitiveness. In: CASSIOLATO, J.; LASTRES, H. (org.) Arranjos produtivos locais e as novas políticas de desenvolvimento industrial e tecnológico. Rio de Janeiro: IE/UFRJ, 2000.

NIU, K. Industrial cluster involvement and organizational adaptation.

Competitiveness Review: An International Business Journal incorporating Journal of Global Competitiveness, v.20, n.5, p.395-406, 2010.

OPRIME, P.; TOLEDO, J.; TRISTÃO, H.; PIMENTA, M. análise dos relacionamentos e cooperação entre empresas do cluster industrial de joias e folheados de Limeira.

Produção Online, v.9, n.4, p.651-674, 2009. 
PETTER, R.; RESENDE, L.; CERANTO, F. Nível de maturidade de arranjos produtivos locais (APL): um diagnóstico no APL de bonés de Apucarana - PR. Produção Online, v.11, n.3, p. 803-822, 2011. http://dx.doi.org/10.14488/16761901.v11i3.875

PORTER, M. Clusters and the new economics of competition. Harvard Business Review, November-December, p.77-90, 1998 (reprint number).

PORTER, M. The Economic Performance of Regions. Institute for Strategy and Competitiveness, Harvard Business School, 2003.

QUADROS, A. O design de móveis de escritório nas pequenas e médias empresas do setor moveleiro na serra gaúcha: um estudo exploratório. Dissertação de Mestrado em Administração. UFRGS, Porto Alegre: 2002.

RODRIGUES, D.; SELLITTO, M. Práticas logísticas colaborativas: o caso de uma cadeia de suprimentos da indústria automobilística. RAUSP, v.43, n.1, p.97-11, 2008.

SANTOS, D; BATALHA, M. Estratégia de produção em arranjos produtivos cerâmicos: o caso de Pedreira (SP). Produção Online, v.10, n.3, p. 599-620, 2010. http://dx.doi.org/10.14488/1676-1901.v10i3.342

SCHIMTZ, H.; NADVI, K. Clustering and Industrialization: introduction. World Development, v.27, n.9, p.1503-1514, 1999. http://dx.doi.org/10.1016/S0305750X(99)00072-8

SCOTT, A. The geographic foundations of industrial performance. In: CHANDLER, A.; HAGSTRON, P.; SOLVELL, O. (Org.) The dynamic firm: the role of technology, strategy, organization, and regions. Oxford: Oxford University Press, 1998.

SIGEOR. Sistema Gerencial Orientado por Resultados. SEBRAE-RS, 2012. Disponível em: http://www.sigeor2008.sebrae.com.br/. Acesso em 20/3/2012.

SILVA, E.; SANTOS, F. Análise do alinhamento da estratégia de produção com a estratégia competitiva na indústria moveleira. Produção, v.15, n.2, p.286-299, 2005. http://dx.doi.org/10.1590/S0103-65132005000200012

SINDMÓVEIS. Sindicato das Indústrias do Mobiliário de Bento Gonçalves. Dados do Setor. Brasil: 2013, Disponível em: http://www.sindmoveis.com.br/portal/downloads/. Acesso em março de 2014.

SONOBE, T., AKOTEN, J., OTSUKA, K. The development of the footwear industry in Ethiopia: How different is it from the East Asian experience? Working Paper. Tokyo: Foundations for Advanced Studies on International Development. 2006. 
SOUZA, M. Clusters como estratégia de desenvolvimento de pequenas e médias empresas: um estudo exploratório do caso moveleiro do município de Colatina - ES. Dissertação de Mestrado em Administração. FGV, São Paulo: 2004.

SUZIGAN, W.; FURTADO, J.; GARCIA, R.; SAMPAIO, S. Aglomerações industriais no estado de São Paulo. Economia Aplicada, v.5, n.4, p.695-717, 2001.

WILK; E.; FENSTERSEIFER; J. Use of resource-based view in industrial cluster strategic analysis. International Journal of Operations \& Prodution Management, v.3, n.9, p.995-1009, 2003.

YIN, R. Estudo de Caso: Planejamento e método. Porto Alegre: Bookman, 2005.

ZELBST, P.; FRANZIER, G.; SÖWER, V. A cluster concentration typology for making location decisions. Industrial Management \& Data Systems, v.110, n.6, p.883-907, 2010. http://dx.doi.org/10.1108/02635571011055108

ZHANG, S.; LI, X. Managerial ties, firm resources and performance cluster firms. Asia Pacific Journal of Management, v.25, n.4, p.615-33, 2008. http://dx.doi.org/10.1007/s10490-008-9090-7

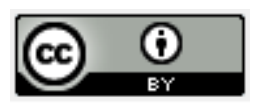

Artigo recebido em 06/06/2012 e aceito para publicação em 26/09/2014

DOI: http://dx.doi.org/ 10.14488/1676-1901.v14i4.1329 